\title{
Fischer-Tropsch Synthesis: Development of a Microkinetic Model for Metal Catalysis
}

\author{
G. Lozano-Blanco', J.W. Thybaut' ${ }^{1}$ K. Surla' ${ }^{2}$, P. Galtier ${ }^{2}$ and G.B. Marin ${ }^{1}$ \\ 1 Laboratorium voor Petrochemische Techniek, Ghent University, Krijgslaan 281-S5, B-9000 Ghent-Belgium \\ 2 Institut français du pétrole, B.P. 3, 69390 Vernaison - France \\ e-mail: gisela.lozano@ugent.be - joris.thybau@@ugent.be - karine.surla@ifp.fr - pierre.galtier@ifp.fr -guy.marin@ugent.be
}

\begin{abstract}
Résumé - La synthèse Fischer-Tropsch : développement d'un modèle microcinétique pour la catalyse sur métaux - L'article présente la construction d'un modèle cinétique par événements constitutifs pour la catalyse sur métaux en utilisant la synthèse Fischer-Tropsch comme exemple. Les modèles cinétiques par événements constitutifs décrivent la distribution complète des produits de réaction avec un nombre réduit de paramètres cinétiques. Un algorithme est nécessaire pour générer toutes les espèces et les réactions élémentaires qui forment le réseau réactionnel. Les réactifs, les intermédiaires et les produits de réaction sont représentés comme matrices Booléennes et labels standardisés. Les paramètres ajustables du modèle sont les enthalpies de chimisorption atomique du carbone, oxygène et hydrogène sur la surface métallique et les coefficients cinétiques de l'événement constitutif des familles de réaction cinétiquement relevantes.
\end{abstract}

\begin{abstract}
Fischer-Tropsch Synthesis: Development of a Microkinetic Model for Metal Catalysis The construction of a single-event microkinetic (SEMK) model for metal catalysis using Fischer-Tropsch synthesis as example reaction is addressed. SEMK's describe the full product distribution with a limited number of kinetic parameters. A computer algorithm is required to generate all the elementary steps and species of the reaction network. Reacting and intermediate species are represented with Boolean matrices and standardized labels. The adjustable model parameters are the atomic chemisorption enthalpies of carbon, oxygen and hydrogen on the metal surface and the single-event kinetic coefficients of the kinetically relevant reaction families.
\end{abstract}




\section{LIST OF SYMBOLS}

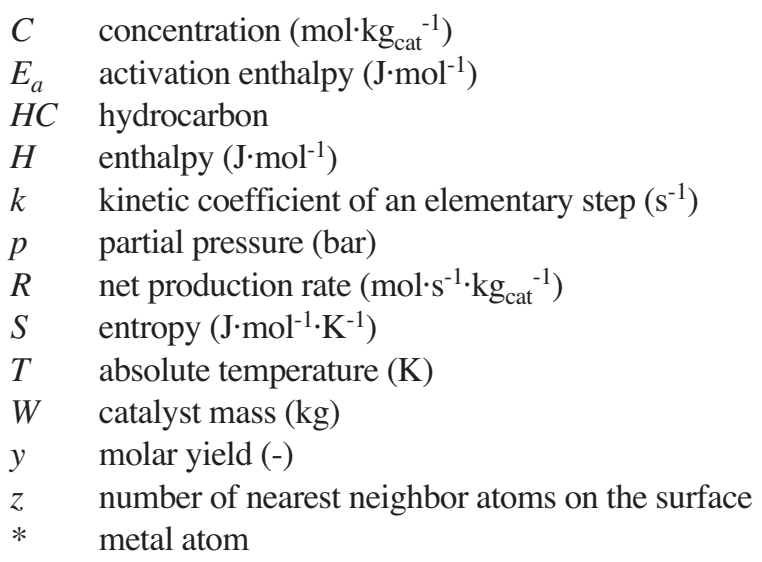

\section{Constants}

$h \quad$ Planck's constant $\left(6.626068 \times 10^{-34} \cdot \mathrm{m}^{2} \cdot \mathrm{kg} \cdot \mathrm{s}^{-1}\right)$

$k_{B} \quad$ Boltzmann constant $\left(1.3806503 \times 10^{-23} \mathrm{~m}^{2} \cdot \mathrm{kg} \cdot \mathrm{s}^{-2} \cdot \mathrm{K}^{-1}\right)$

$R \quad$ universal gas constant $\left(8.3144 \mathrm{~J} \cdot \mathrm{mol}^{-1} \cdot \mathrm{K}^{-1}\right)$

\section{Greek symbols}

\section{$\Delta \quad$ difference}

$\sigma \quad$ symmetry number

$\Sigma$ sum

$v \quad$ stoichiometric coefficient

\section{Subscripts}

$\begin{array}{ll}\text { cat } & \text { catalyst } \\ \text { chem } & \text { alkene chemisorption reaction } \\ \text { des } & \text { desorption reaction } \\ \text { ext } & \text { external contribution } \\ f & \text { formation } \\ g l & \text { global } \\ \text { ini } & \text { initial } \\ \text { int } & \text { internal contribution } \\ M & \text { metal atom } \\ \text { oa } & \text { oxidative addition reaction } \\ R & \text { reaction } \\ r e & \text { reductive elimination reaction } \\ \text { rot } & \text { rotational contribution } \\ \text { surf } & \text { metal surface } \\ \text { tot } & \text { total }\end{array}$

\section{Superscripts}

$\mathrm{n}$ number of chiral carbon atoms in the molecule

$\sim$ single-event

$\neq \quad$ transition state

$0 \quad$ standard state (1 bar)

\section{INTRODUCTION}

Fischer-Tropsch synthesis can be considered as the hydrogenation of carbon monoxide to produce clean transportation fuels and chemicals. The feedstock consists of a mixture of $\mathrm{H}_{2}$ and $\mathrm{CO}$, also denoted as syngas, and can be obtained from any carbonaceous sources. The depleting reserves of crude oil and the awareness that less expensive transportation fuels can be obtained from coal, "stranded" natural gas or biomass, has substantially increased the interest in Fischer-Tropsch synthesis in the last decade. Furthermore, one of the potential advantages of this technology is the high product diversity ranging from fuels to high value chemical products [1].

Increasing computer capabilities and a better understanding of the fundamental chemistry in heterogeneous and organometallic chemistry inspire the construction of microkinetic models for metal catalysis [2-4]. Microkinetic models calculate the rate of every elementary step. Hence, the knowledge of the reaction pathways of every reacting and intermediate species is required. However, for over 80 years, the mechanistic details of the Fischer-Tropsch synthesis have been a matter of controversy [5]. Only the chain growth through the step-wise addition of single carbon monomers is not a matter of discussion. The reason for this agreement is that the carbon number product distribution can be mathematically described by the so-called Anderson-Schulz-Flory polymerization reaction mechanism [6]. This expression follows from the independency of the chain growth probability from the carbon number of the chemisorbed species.

Similar to most of the petroleum related reactions, the elementary steps in Fischer-Tropsch synthesis act on homologous series of compounds, i.e., reaction rates are determined by the reactive moiety, rather than by the entire species. The main advantage of single-event microkinetic (SEMK) models is that they preserve the fundamental character of the model while only using a limited number of adjustable kinetic parameters. SEMK's separate the symmetry aspects of the structural effects on the kinetic coefficient leading to a so-called single-event kinetic coefficient which is unique for a reaction family [7]. SEMK's have been already applied to acid catalyzed reactions such as catalytic cracking and hydrocracking $[8,9]$. In this work, the extension of a SEMK model to metal catalysis is established. In particular, the steps followed for the construction of a SEMK model for FischerTropsch synthesis are presented.

\section{METHODOLOGY}

\subsection{Mechanism Elucidation}

The first step towards the formulation of a SEMK model for metal catalysis is the knowledge of the reaction mechanism in molecular detail. Fischer-Tropsch synthesis is a 
polymerization reaction where the chain growth occurs through step-wise addition of $\mathrm{C}_{1}$ species. However, the nature of these building-blocks and of the reacting surface species is still under discussion. Several reaction mechanisms have been proposed since this reaction was discovered in the 1920's [5].

The so-called "carbene" mechanism consists of the insertion of methylene species into growing metal-alkyl species, and is the most popular mechanism for Fischer-Tropsch synthesis. This reaction family is generally accepted in heterogeneous catalysis $[10,11]$. Other reaction families which are analogous to well-known reactions in organometallic chemistry such as reductive elimination and $\beta$-hydride elimination are assumed to be responsible for the formation of $n$-alkanes and 1-alkenes $[12,13]$, vide Figure 1. These reaction families are those of interest from the SEMK point of view. The remaining elementary reactions in the Fischer-Tropsch synthesis reaction network, which cannot be grouped into reaction families, are involved in the formation of the primary building-blocks such as methylene and methyl species, and water. The so-called chain initiation reactions, i.e., the formation of the building-blocks, arise from the consecutive hydrogenation of carbide species obtained from the chemisorption and dissociation of $\mathrm{CO}$ :

$$
\begin{gathered}
\mathrm{H}_{2}+* * \leftrightarrow 2 * \mathrm{H} \\
\mathrm{CO}+* * \leftrightarrow * * \mathrm{CO} \\
* * \mathrm{CO}+* * * \leftrightarrow * * * \mathrm{C}+* * \mathrm{O} \\
* * * \mathrm{C}+* \mathrm{H} \leftrightarrow * * * \mathrm{CH}+* \\
* * * \mathrm{CH}+* \mathrm{H} \leftrightarrow * * \mathrm{CH}_{2}+* * \\
* * \mathrm{CH}_{2}+* \mathrm{H} \leftrightarrow * \mathrm{CH}_{3}+* *
\end{gathered}
$$

where $*$ represents one metal atom on the surface.

The elementary steps involved in the formation of water are:

$$
\begin{aligned}
& * * \mathrm{O}+* \mathrm{H} \leftrightarrow * \mathrm{OH}+* * \\
& * \mathrm{OH}+* \mathrm{H} \leftrightarrow \mathrm{H}_{2} \mathrm{O}+* *
\end{aligned}
$$

The fundamental character of the kinetic model requires a detailed investigation of the intermediate species involved in the reaction steps. The general rule is to assume that the preferred binding site for the $\mathrm{CH}_{x}$-species on the metal is the one which allows the carbon atom to have 4- $\sigma$ bonds [14].

It is generally accepted that $n$-alkanes and 1 -alkenes are primary products and that the re-adsorption of 1-alkenes yields branched hydrocarbons and internal-alkenes [5]. Methyl-branched hydrocarbons are formed by methylene insertion into secondary or tertiary metal-alkyl species, vide Figure 1.

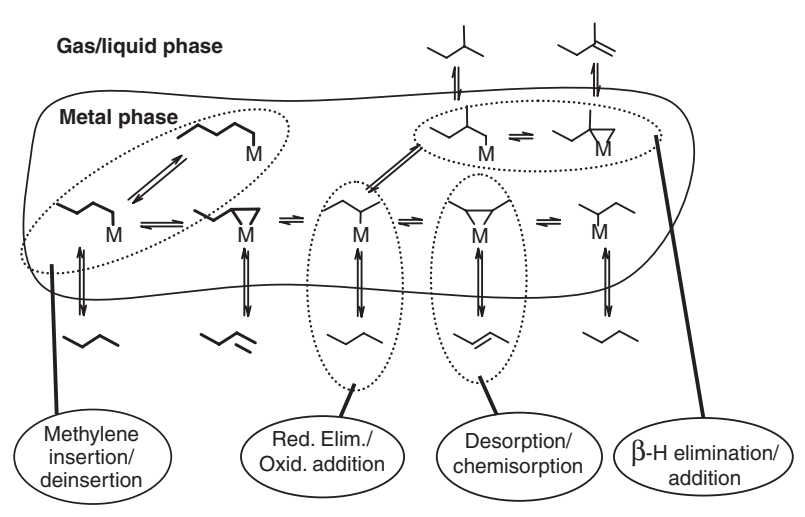

Figure 1

Reaction families considered in the chain growth and chain termination of Fischer-Tropsch synthesis.

\subsection{Automatic Generation of the Reaction Network}

A computer algorithm is required for the generation of all the elementary steps and species involved in the reaction network of Fischer-Tropsch synthesis. The numerical representation of the different species is based upon Boolean relation matrices [15] and standardized labels [7]. Alternative automatic reaction network generation programs have also been constructed for Fischer-Tropsch synthesis $[3,16]$.

In Figure 2 the Boolean representation of a secondary metal-alkyl and the corresponding standardized label is given. Each element in the binary relation matrix stands for the existence of a bond between the atoms in the molecule. If a bond exists, the corresponding matrix element is equal to one. Otherwise the matrix element is equal to zero. For unsaturated species, an additional information vector is required. If carbon atom $i$ is unsaturated the element in the additional vector is equal to one. In order to account for atoms different than carbon in the molecule, an adjacent column was added to the left border of the Boolean matrix [7], vide Figure 2. The metal atom is hence accounted for explicitly in the Boolean matrix representation.

Boolean matrices require large computer memory and are difficult to read. Standardized labels offer a more compact alternative to store the generated molecules. The main advantage of the Boolean matrices is the easy operability when performing the elementary reactions. The Boolean matrix operation to be performed for a $\beta$-hydride elimination is displayed in Figure 3. The only modification in the Boolean matrix of the products is the new generated bond. The sum of the elements in a row is the degree of substitution of the atom. The transformation from the Boolean matrix to the standardized label is straightforward. 
<smiles>[M]C(C)C(C)C(C)CC</smiles>

a)

$\left[\begin{array}{lllllllll}0 & & & & & & & & \\ 1 & 1 & 3 & 3 & 3 & 2 & 1 & 1 & 1 \\ 1 & 4 & 2 & 4 & 4 & 4 & 4 & 4 & 4\end{array}\right]$

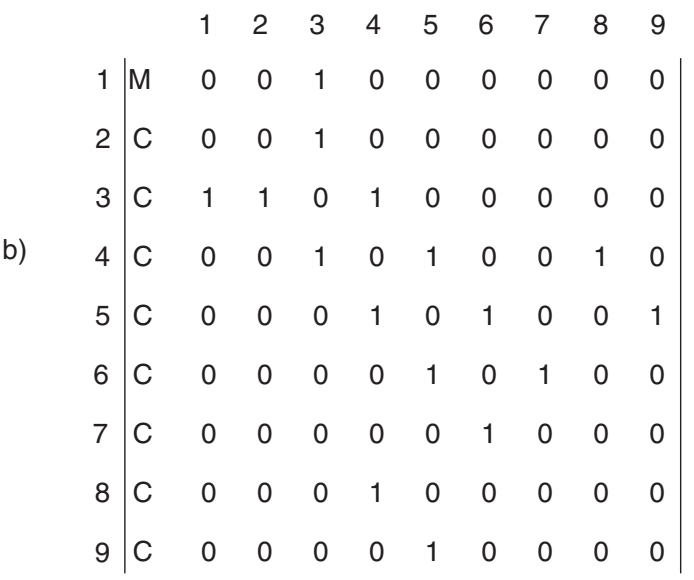

Figure 2

a) Standardized label and b) Boolean matrix for the 3,4-dimethylhexan-2-yl metal species.

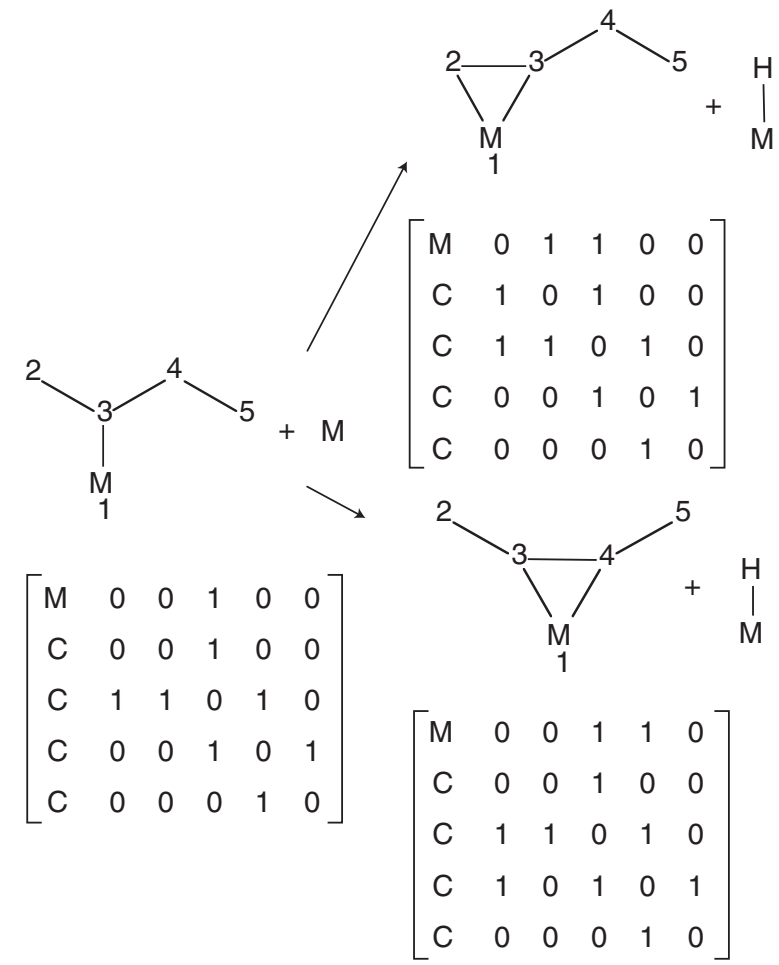

Figure 3

Boolean matrix transformations for the $\beta$-hydride elimination of butan-2-yl metal species.
The standardized labels are vectors that unequivocally represent the molecule. The elements in the vector given in Figure 2 are arranged in 3 rows. The element of the first row represents the position of the charge if existing on the hydrocarbon structure. The elements of the second row indicate the degree of substitution of the atoms, i.e., 1 stands for a primary atom, 2 for a secondary atom, etc. And the elements of the third row define the character of the corresponding atoms by means of the code numbers given in Table 1. These code numbers are related to the degree of priority of the atoms in the molecule. In order to preserve the uniqueness of the Boolean and vector representation, the atoms are numbered following a strict set of priority rules, based on IUPAC specifications.

\section{TABLE 1}

Code numbers used in the standardized labels to identify the atoms in molecules involved in Fischer-Tropsch synthesis

\begin{tabular}{c|c}
\hline Code number & Atom character \\
\hline 1 & Metal atom bonded to a carbon atom \\
2 & Carbon atom bonded to a metal atom \\
3 & Unsaturated carbon atom \\
4 & Saturated carbon atom \\
\hline
\end{tabular}

For the surface species the numbering starts with the metal atom.

Next, the carbon atom(s) bonded to the metal must have the lowest possible number.

Carbon atoms belonging to the longest chain are numbered first and subsequently the carbon atoms in the branches.

Alkenes are treated in such a way that the unsaturated carbon atoms have the smallest number.

Branched hydrocarbons are numbered in order to obtain the smallest number for the carbon atom that bears the methyl group.

The generation and reaction of every intermediate species is guaranteed by a counter-based "while" loop. The program generates all possible forward and reverse elementary steps for Fischer-Tropsch synthesis shown in Figure 1. Switch indexes have been included in the algorithm in order to control the characteristics of the products. The maximum chain length of the individual group of hydrocarbon families as well as the position of the double bond in the molecules or the number of branches can be specified. Other features such as the selective chemisorption of 1-alkenes or internalalkenes can also be controlled. 
For a maximum hydrocarbon chain length of 8,10 or 12 carbon atoms the number of metal-alkyl species, alkanes and alkenes as well as the number of elementary steps generated in the program are given in Table 2.

\section{TABLE 2}

Number of species and elementary steps generated for reaction networks with alkanes and alkenes up to 8,10 and 12 carbon number

\begin{tabular}{c|c|c|c|c}
\hline $\begin{array}{c}\text { Chain length } \\
\text { (max. C atom) }\end{array}$ & \multicolumn{2}{|c|}{$\begin{array}{c}\text { Number of generated species } \\
\text { Metal-alkyls }\end{array}$} & $\begin{array}{c}\text { Alkanes } \\
\text { Alkenes of generated } \\
\text { elementary steps }\end{array}$ \\
\hline 8 & 131 & 36 & 94 & 922 \\
10 & 528 & 107 & 390 & 3730 \\
12 & 2084 & 334 & 1571 & 14752 \\
\hline
\end{tabular}

\subsection{Single-Event MicroKinetics (SEMK)}

The single-event concept [7] drastically reduces the number of adjustable kinetic parameters preserving the fundamental character of a microkinetic model.

\subsubsection{The Single-Event Concept}

The rate coefficient based on the transition state theory [17] describes the transformation of a reactant into a product as a function of the entropy and enthalpy change between the reactant and the transition state species:

$$
k=\frac{k_{B} T}{h} \exp \left(\frac{\Delta S^{0, \neq}}{R}\right) \exp \left(-\frac{\Delta H^{0, \neq}}{R T}\right)
$$

The standard entropy contains among others rotational contributions that comprise an intrinsic term and the symmetry number of the molecule:

$$
S_{r o t, e x t / i n t}^{0}=\tilde{S}_{r o t}^{0}-R \ln \sigma_{e x t / \text { int }}
$$

The global symmetry number accounts also for the $n$ chiral centers of the molecule:

$$
\sigma_{g l}=\frac{\sigma_{e x t} \sigma_{i n t}}{2^{n}}
$$

The kinetic coefficient can be split up into a symmetry dependent factor, i.e., the ratio between the global symmetry number of the reactant and transition state, and a second factor, the so-called single-event rate coefficient $\tilde{k}$ :

$$
\begin{gathered}
k=\frac{\sigma_{g l, r}}{\sigma_{g l, \neq}} \frac{k_{B} T}{h} \exp \left(\frac{\Delta \tilde{S}^{0, \neq}}{R}\right) \exp \left(-\frac{\Delta H^{0, \neq}}{R T}\right) \\
k=\frac{\sigma_{g l, r}}{\sigma_{g l, \neq}} \tilde{k}
\end{gathered}
$$

The ratio between the global symmetry numbers describes the symmetry related structural differences of reactants and transition state species within a reaction family. Global symmetry numbers of reactant and transition state species are calculated simultaneously in the network generation program. In particular, the external rotational symmetry number $\sigma_{e x t}$ from the global symmetry number arises from the contributions to the entropy achieved by changing the orientation of the molecular axis of the molecule in the space [18]. Regarding the calculation of this external symmetry number, the catalyst is assumed to be symmetrical and uniform. This means that perpendicular symmetry axes in the adsorbate are preserved during the chemisorption process while parallel symmetry axes are lost.

Global symmetry numbers must be investigated carefully since an incorrect calculation can lead to inaccurate hydrocarbon selectivities.

The single-event kinetic coefficient for a given type of elementary step can be assumed constant. The number of adjustable parameters in a single-event microkinetic model amounts to the number of reaction families. The number of reaction families depends on the nature of the species involved, e.g., on the primary, secondary or tertiary character of the reacting metal alkyl. The number of adjustable singleevent kinetic coefficients for the chain growth and termination reactions shown in Figure 1 equals 8, including forward and reverse reactions, if only primary products are obtained, i.e., $\mathrm{n}$-alkanes and 1-alkenes. If branched hydrocarbons are also present in the product distribution, secondary or tertiary metal alkyl species are also involved in the reaction mechanism and the number of adjustable kinetic parameters increases.

\subsubsection{Single-Event Rate Equations}

Net formation rates are written for every product in the reaction network. In order to calculate the concentration of the intermediate species, the pseudo-steady state approximation is applied to the latter. The probability of finding adjacent occupied or unoccupied atoms [19] is included also in the rate expressions.

The net formation rate of an alkane $l$ is given by:

$$
\begin{array}{r}
R_{\text {alkane }, l}=\sum_{i=1}^{n m a l k y l s} \frac{1}{2} z \frac{\sigma_{g l, r}}{\sigma_{g l, \neq}} \tilde{k}_{r e, M-\text { alkyls }} C_{M-\text { alkyl }, i \rightarrow l} \frac{C_{M-H}}{C_{M_{\text {tot }}}} \\
-\frac{1}{2} z \frac{\sigma_{g l, r}}{\sigma_{g l, \neq}} \tilde{k}_{\text {oa,alkanes }} p_{\text {alkane }, l} C_{M} \frac{C_{M}}{C_{M_{\text {tot }}}}
\end{array}
$$

The net rate of formation of an alkene $k$ is given by:

$$
\begin{aligned}
R_{\text {alkene }, k} & =\frac{\sigma_{g l, r}}{\sigma_{g l, \neq}} \tilde{k}_{\text {des }, M \text {-alkenes }} C_{M-\text { alkene }, j \rightarrow k} \\
& -\frac{\sigma_{g l, r}}{\sigma_{g l, \neq}} \tilde{k}_{\text {chem }} p_{\text {alkene }, k} C_{M}
\end{aligned}
$$


The temperature dependence of the single-event rate coefficients, vide equations (12) and (13), is expressed through the Arrhenius relationship. As a result, two types of kinetic parameters are differentiated: the single-event pre-exponential factor and activation enthalpy. Single-event pre-exponential factors are calculated via statistical thermodynamics. Activation enthalpies are calculated with a semiempirical approach $[20,21]$. These activation enthalpies must be refined via regression of experimental data.

\subsubsection{Thermodynamic Consistency}

Apart from the introduction of the reaction family concept, the number of kinetic parameters can be further reduced by applying the principle of microscopic reversibility. Activation enthalpies and single-event pre-exponential factors for a reverse elementary step $i$, are calculated as:

$$
\begin{aligned}
& E_{a, i}^{r e v}=E_{a, i}^{f o r}-\Delta H_{R, i}^{0} \\
& \tilde{A}_{i}^{r e v}=\frac{\tilde{A}_{i}^{f o r}}{\exp \left(\frac{\Delta \tilde{S}_{R, i}^{0}}{R}\right)}
\end{aligned}
$$

Enthalpies and entropies of surface reactions are linear combinations of enthalpies and entropies of formation of surface species and analogous gas-phase species. The standard enthalpy of a surface reaction is defined as:

$$
\begin{array}{r}
\Delta H_{R, \text { surf }}^{0}=\Delta H_{R, \text { gas }- \text { phase }}^{0} \\
+\sum_{j=1}^{\text {react }} v_{j} \Delta H_{\text {chem }, j}^{0} \\
-\sum_{k=1}^{\text {prod }} v_{k} \Delta H_{\text {chem }, k}^{0}
\end{array}
$$

where the enthalpy of the analogous surface reaction in gasphase is:

$$
\Delta H_{R, \text { gas-phase }}^{0}=\sum_{k=1}^{\text {prod }} v_{k} \Delta_{f} H_{\mathrm{k}}^{0}-\sum_{j=1}^{\text {react }} v_{j} \Delta_{f} H_{j}^{0}
$$

The same type of equations holds for the calculation of standard entropies of surface reactions. Enthalpies and entropies of the analogous surface species in gas-phase are calculated with an in-house algorithm based on Benson's group additivity values for alkanes, alkenes and radical species [18, 22-24]. Gas-phase empirical data for the molecules involved in the chain initiation reactions (equations (1) to (8)) are taken from tabulated values [25].

Chemisorption enthalpies are calculated as a function of gas-phase bond energies and atomic chemisorption enthalpies [20]. The unity bond index-quadratic exponential potential (UBI-QEP) method is based on a small number of well-defined assumptions and requires very few parameters that can be obtained from experimental observations. Experience with the UBI-QEP method has shown that it yields chemisorption enthalpies and activation enthalpies for various elementary reactions that are close to experimental results [26]. Atomic chemisorption enthalpies are dependent on the metal surface and are assumed as adjustable parameters in the SEMK model.

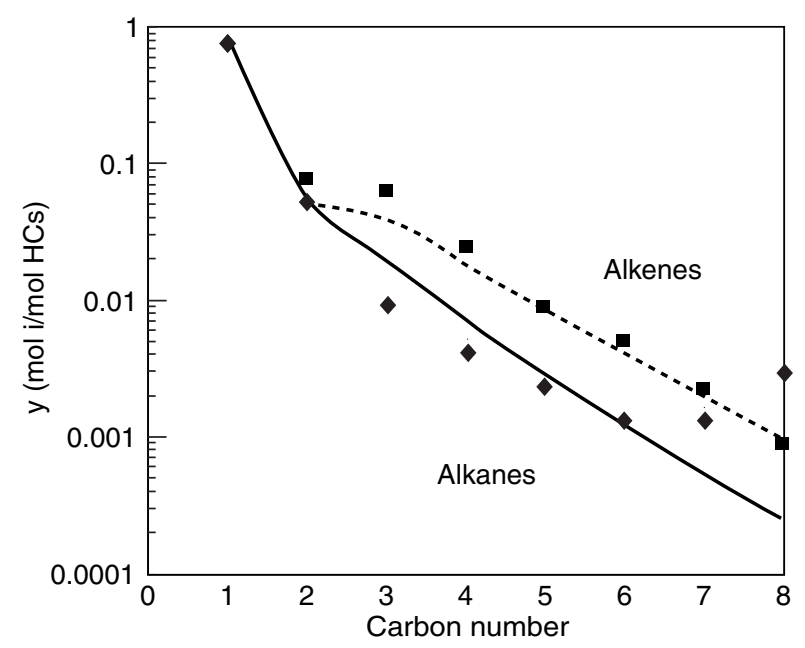

Figure 4

Calculated (lines) and experimental (symbols) [30] molar yields for alkanes and 1 -alkenes up to 8 carbon atoms $\left(\mathrm{T}=623 \mathrm{~K}, \mathrm{H}_{2} / \mathrm{CO}=2, \mathrm{p}_{\mathrm{t}}=6 \mathrm{bar}, \mathrm{W} / \mathrm{F}_{\mathrm{CO} \text { ini }}=18 \mathrm{~kg} \cdot \mathrm{s} \cdot \mathrm{mol}^{-1}\right)$.

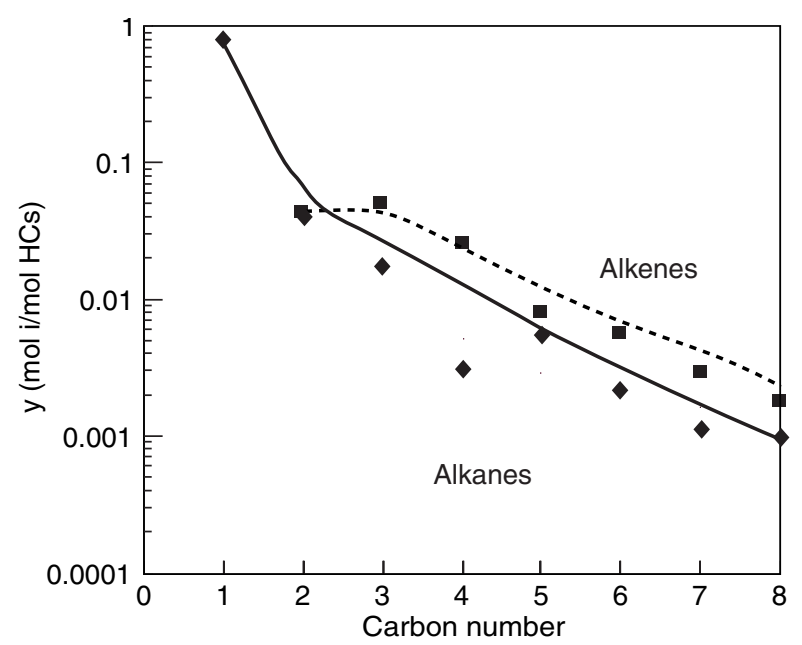

Figure 5

Calculated (lines) and experimental (symbols) [30] molar yields for alkanes and 1 -alkenes up to 8 carbon atoms $\left(\mathrm{T}=623 \mathrm{~K}, \mathrm{H}_{2} / \mathrm{CO}=3, \mathrm{p}_{\mathrm{t}}=11 \mathrm{bar}, \mathrm{W} / \mathrm{F}_{\mathrm{CO} \text { ini }}=12 \mathrm{~kg} \cdot \mathrm{s} \cdot \mathrm{mol}^{-1}\right)$. 


\section{APPLICATION EXAMPLE ON AN IRON-BASED CATALYST}

Simulations are performed for Fischer-Tropsch synthesis using an iron-based catalyst. The water-gas shift reaction is important on iron-based catalysts under Fischer-Tropsch conditions. The hydrocarbon forming reactions take place on the carbide phase of the catalyst while the water-gas shift occurs on the oxide phase [27, 28]. Six elementary reactions are involved in the reaction mechanism for the water-gas shift [29].

Some of the elementary reactions are close to equilibrium at the operating conditions investigated. This can be assessed through the calculation of the affinities for the elementary reactions involved [19]. Only the kinetic parameters pertaining to kinetically significant elementary reactions, i.e., those with affinities significantly different from 0 , have to be obtained by regression.

The number of adjustable parameters in this case amounts to 12 , i.e., the atomic chemisorption enthalpies of carbon, hydrogen and oxygen atom on the iron carbide phase, the chemisorption enthalpy of hydrogen atom on the iron oxide phase, and the activation enthalpies of the kinetically significant reaction families or elementary reactions in FischerTropsch synthesis.

These parameters can be adjusted manually or can be estimated via regression of experimental data. Examples of experimental and simulated molar yields of alkanes and alkenes are given in Figures 4, 5.

\section{CONCLUSIONS}

Single-Event MicroKinetics have been extended to metal catalysis, in particular to Fischer-Tropsch synthesis. The first step towards the formulation of a SEMK model is the construction of the reaction network in terms of elementary steps. Fischer-Tropsch synthesis involves a large number of species and elementary steps and hence, the reaction network must be generated by means of a computer algorithm. The representation of the species in the program is based on the Boolean concept and standardized labels. The number of adjustable parameters in the first instance is equal to the number of reaction families. By following the principle of microscopic reversibility the number of adjustable kinetic parameters can be reduced. Standard enthalpies of reaction are calculated as a function of three adjustable parameters: chemisorption enthalpies of carbon, hydrogen and oxygen on the metal catalyst. Standard entropies of reaction and preexponential factors are calculated via statistical thermodynamics. By studying the quasi-equilibration of the elementary steps, the number of adjustable parameters can be further reduced accounting only for the kinetically relevant elementary reactions. Simulations using an iron-based catalyst have shown that a limited number of adjustable parameters suffices to accurately simulate Fischer-Tropsch synthesis.

\section{ACKNOWLEDGEMENTS}

G. Lozano-Blanco acknowledges the Institut français du pétrole for financial support.

This research has been partly carried out in the framework of the Interuniversity Attraction Poles Programme funded by the Belgian Science Policy.

\section{REFERENCES}

1 Steynberg A.P. (2004) Introduction to Fischer-Tropsch technology, in Fischer-Tropsch technology, Studies in Surface Science and Catalysis, 152, Steynberg A.P. and Dry M. (Eds.), Elsevier, Amsterdam.

2 Dumesic J.A., Rudd D.F., Aparicio L.M., Rekoske J.E. and Treviño A.A. (1993) The Microkinetics of Heterogeneous Catalysis, American Chemical Society, Washington.

3 Klinke II D.J. and Broadbelt L.J. (1999) Construction of a mechanistic model for Fischer-Tropsch synthesis on $\mathrm{Ni}(100)$ and Co(1000) surfaces, Chem. Eng. Sci., 54, 3379-3389.

4 Lozano-Blanco G., Thybaut J.W., Surla K., Galtier P. and Marin G.B. (2005) Single-Event MicroKinetics for FischerTropsch synthesis on iron-based catalysts, EuropaCat-VII, Sofia, Bulgaria, August 28-September 1.

5 Claeys M. and van Steen E. (2004) Basic Studies, in FischerTropsch technology, Studies in Surface Science and Catalysis, 152, Steynberg A.P. and Dry M. (Eds.), Elsevier, Amsterdam.

6 Anderson R.B. (1984) The Fischer-Tropsch Synthesis, Academic Press, New York.

7 Vynckier E. and Froment G.F. (1991) Modeling of the Kinetics of Complex Processes Based upon Elementary Steps, in Kinetic and Thermodynamic Lumping of Multicomponent Mixtures, Astarita G. and Sandler S.I. (Eds.), Elsevier, Amsterdam.

8 Quintana-Solórzano R., Thybaut J., Marin G.B., Lødeng R. and Holmen A. (2005) Single-Event MicroKinetics for coke formation in catalytic cracking, Catal. Today, 107-108, 619-629.

9 Martens G.G., Thybaut J.W. and Marin G.B. (2001) Singleevent rate parameters for the hydrocracking of cycloalkanes on Pt/US-Y zeolites, Ind. Eng. Chem. Res., 40, 1832-1944.

10 Bent B.E. (1996) Mimicking aspects of heterogeneous catalysis: generating, isolating, and reacting proposed surface intermediates on single crystals in vacuum, Chem. Rev., 96, 1361-1390.

11 Toyir J., Leconte M., Niccolai G.P. and Basset J.-M. (1995) Hydrogenolysis and Homologation of 3,3-dimethyl-1-butene on $\mathrm{Ru} / \mathrm{SiO}_{2}$ catalyst: implications for the mechanism of carbon-carbon bond formation and cleavage on metal surfaces, J. Catal., 152, 306-312.

12 Overett M.J., Hill R.O. and Moss J.R. (2000) Organometallic chemistry and surface science: mechanistic models for the Fischer-Tropsch synthesis, Coordin. Chem. Rev., 206-207, 581-605.

13 Zaera F. (2002) Selectivity in hydrocarbon catalytic reforming: a surface chemistry perspective, Appl. Catal. A-Gen., 229, 75-91.

14 Kua J., Faglioni F. and Goddard III W.A. (2000) Thermochemistry for hydrocarbon intermediates chemisorbed on metal surfaces: $\mathrm{CHn}-\mathrm{m}(\mathrm{CH} 3)(\mathrm{m})$ with $\mathrm{n}=1,2,3$ and $\mathrm{m} \leq \mathrm{n}$ on Pt, Ir, Os, Pd, Ph, and Ru , J. Am. Chem. Soc., 122, 23092321 . 
15 Baltanas M.A. and Froment G.F. (1985) Computer Generation of reaction networks and calculation of product distributions in hydroisomerization and hydrocracking of paraffins on Pt-containing bifunctional catalysts, Comput. Chem. Eng., 9, 71-81.

16 Temkin O.N., Zeigarnik A.V., Kuz'min A.E., Bruk L.G. and Slivinskii E.V. (2002) Construction of the reaction networks for heterogeneous catalytic reactions: Fischer-Tropsch synthesis and related reactions, Russ. Chem. B., 51, 1-36.

17 Eyring H. (1935) The activated complex and the absolute rate of chemical reactions, Chem. Rev., 17, 65-77.

18 Benson S.W. (1968) Thermochemical Kinetics, Wiley, New York.

19 Boudart M. and Diéga-Mariadassou G. (1982) Cinétique des réactions en catalyse hétérogène, Masson, Paris.

20 Shustorovich E. and Sellers H. (1998) The UBI-QEP method: a practical theoretical approach to understanding chemistry on transition metal surfaces, Surf. Sci.Rep., 31, 1-119.

21 Vannice M.A. (2005) Kinetics of Catalytic Reactions, Springer, New York.

22 Cohen N. and Benson S.W. (1993) Estimation of heats of formation of organic compounds by additivity methods, Chem. Rev., 93, 2419-2438.
23 Cohen N. (1996) Revised group additivity values for enthalpies of formation (at $298 \mathrm{~K}$ ) of carbon-hydrogen and carbon-hydrogen-oxygen compounds, J. Phys. Chem. Ref. data, 25, 1411-1481.

24 Cohen N. (2002) Thermochemistry of alkyl free radicals, J. Phys. Chem., 96, 9052-9058.

25 http://webbook.nist.gov/chemistry

26 Bezinger J.B. (1991) Thermochemical methods for reaction energetics on metal surfaces, in Metal-surface reaction energetics, Shustorovich E. (Ed.), VCH, New York.

27 Lox E.S., Marin G.B., De Grave E. and Bussiére P. (1988) Characterization of a promoted precipitated iron catalyst for Fischer-Trospch synthesis, Appl. Catal., 40, 197-218.

28 Lox E.S. and Froment G.F. (1993) Kinetics of the Fischer Tropsch reaction on a precipitated promoted iron catalyst 2 . Kinetic modeling, Ind. Eng. Res., 32, 71-82.

29 Rethwisch D.G. and Dumesic J.A. (1986) The effect of metal-oxygen bond strength on properties of oxides: II. Water Gas Shift over supported iron and zinc oxides, J. Catal., 101, 35-42.

30 Lox E. (1987) De synthese van koolwaterstoffen uit koolstofmonoxyde en waterstof, $P h D$ Thesis, Ghent University.

Final manuscript received in June 2006 